\title{
Expression levels of IL-17 and TNF- $\alpha$ in degenerated lumbar intervertebral discs and their correlation
}

\author{
XIAO-GANG LIU ${ }^{1}$, HONG-WEI HOU ${ }^{2}$ and YI-LIN LIU ${ }^{3}$ \\ Departments of ${ }^{1}$ Orthopedics and ${ }^{2}$ Information, Weihai Hospital of Qingdao University, Weihai, Shandong 264200; \\ ${ }^{3}$ Department of Internal Medicine, Worker's Hospital of Xinjiang Dushanzi Mining Area Services Division, \\ Karamay, Xinjiang 833699, P.R. China
}

Received December 8, 2014; Accepted December 3, 2015

DOI: $10.3892 /$ etm.2016.3250

\begin{abstract}
The present study aimed to investigate the expression and roles of interleukin (IL)-17 and tumor necrosis factor (TNF) $-\alpha$ in intervertebral disc degeneration (IDD) and to identify the association between the effects of IL-17 and TNF- $\alpha$ in IDD. This may increase understanding of the pathogenic mechanism underlying IDD, and aid the development of alternative therapies. The experimental group consisted of 40 samples of nucleus pulposus tissue obtained from the intervertebral discs (IVDs) of patients with IDD by surgical intervention, and was further divided into an annulus fibrosus disrupted group, comprising 18 patients in which the external annulus was ruptured, and an annulus fibrosus intact group comprising 22 patients. The control group consisted of 20 samples of nucleus pulposus tissue from the IVDs of patients with traumatic lumbar disc fractures. The mRNA and protein expression levels of IL-17 and TNF- $\alpha$ in the 50 tissue samples were detected by semi-quantitative reverse transcription polymerase chain reaction and immunohistochemical staining, respectively, and the results were statistically analyzed. The IL-17 and TNF- $\alpha$ protein and mRNA expression levels in the annulus fibrosus disrupted and annulus fibrosus intact groups were both higher compared with those in the control group. In addition, the expression levels of IL-17 and TNF- $\alpha$ in the annulus fibrosus disrupted group were significantly higher compared with those in the annulus fibrosus intact group $(\mathrm{P}<0.01)$. A positive correlation was identified between the mRNA and protein expression levels of IL-17 and TNF- $\alpha$ in the experimental group ( $\mathrm{r}=0.957, \mathrm{P}<0.01)$. IL-17 and TNF- $\alpha$ may therefore be involved in the progression of human IDD, and may have synergistic effects in the development of IDD.
\end{abstract}

Correspondence to: Professor Xiao-Gang Liu, Department of Orthopedics, Weihai Hospital of Qingdao University, 51 Guangming Road, Weihai, Shandong 264200, P.R. China E-mail: liuxiaogang904@126.com

Key words: interleukin-17, tumor necrosis factor- $\alpha$, intervertebral disc, intervertebral disc degeneration

\section{Introduction}

The intervertebral disc (IVD) is a complex tissue located between two bony vertebrae, which is composed of a centrally located hydrated nucleus pulposus, a peripherally located elastic and fibrous annulus fibrosus, and cartilaginous endplates (1). Intervertebral disc degeneration (IDD) is the leading cause of lower back pain and certain other disc disorders, and is associated with a reduction in proteoglycan and type II collagen levels and an increase in type I collagen levels in the nucleus pulposus $(2,3)$. Consequently, IDD leads to spinal degenerative diseases, including lumbar disc herniation (LDH), the most common degenerative spine disease in elderly people $(4,5)$. The symptoms of LDH include lower back pain, weakness, numbness, pain and tingling in the leg or foot, and cauda equina syndrome (6). The incidence of LDH is higher in developing countries, particularly in China, and the rate of LDH remains $\sim 3-13 \%$ (7). Similarly to other complex diseases, the etiology of LDH includes both hereditary and environmental factors $(8,9)$. Hereditary factors include family history, and occupational factors are among the most significant environmental factors, including lumbar load, heavy physical work, and bending over or twisting $(10,11)$. Previous studies have demonstrated that inflammatory cells and inflammatory medium are present in degenerative lumbar disc tissue, including interleukin (IL)-17 and tumor necrosis factor (TNF)- $\alpha$, which are associated with the degeneration of $\mathrm{LDH}$ and hence the pathogenesis of IDD (12-14).

IL-17 is a signature cytokine of T helper 17 cells, which induces the activation and mobilization of neutrophils, and triggers the production of chemokines and pro-inflammatory cytokines through cellular targets $(15,16)$. IL-17 includes six family members, IL-17A-F, which have roles in the maturation of hematopoietic progenitor cells $(16,17)$. Excessive or inappropriate production of IL-17 is associated with various disorders or diseases, including asthma, rheumatoid arthritis, ulcerative colitis, IDD, other autoimmune or inflammatory diseases and cancer (18). Along with TNF- $\alpha$ and interferon- $\gamma$, IL-17 expression has been demonstrated to be elevated in herniated and IDD tissue samples, which suggested that IL-17 has an important role in IDD (19).

TNF- $\alpha$ is an inflammatory cytokine is important in cell growth and death, tumor formation, stress response and 
Table I. Disc degeneration characteristics as determined by T2-weighted magnetic resonance imaging.

\begin{tabular}{|c|c|c|c|c|}
\hline Grade & Structure & $\begin{array}{c}\text { Nucleus } \\
\text { and annulus } \\
\text { distinction }\end{array}$ & Signal intensity & $\begin{array}{l}\text { Height of } \\
\text { intervertebral disc }\end{array}$ \\
\hline I & Homogeneous, bright white & Clear & $\begin{array}{l}\text { Hyperintense, isointense to } \\
\text { cerebrospinal fluid }\end{array}$ & Normal \\
\hline II & $\begin{array}{l}\text { Inhomogeneous with or } \\
\text { without horizontal bands }\end{array}$ & Clear & $\begin{array}{l}\text { Hyperintense, isointense to } \\
\text { cerebrospinal fluid }\end{array}$ & Normal \\
\hline III & Inhomogeneous, gray & Unclear & Intermediate & Normal to slightly decreased \\
\hline IV & Inhomogeneous, gray to black & Absent & Intermediate to hypointense & Normal to moderately decreased \\
\hline V & Inhomogeneous, black & Absent & Hypointense & Collapsed disc space \\
\hline
\end{tabular}

immune response $(20,21)$. The predominant functions of TNF- $\alpha$ include upregulating the activity of matrix metalloproteinases (MMPs) and the expression of genes, reducing the synthesis of collagen and proteoglycans, stimulating the inflammatory response and the production of other cytokines such as IL-1, IL-6, IL-8 and prostaglandin E2, promoting cell migration and improving the permeability of endothelial cells (22-24). One of the basic pathological changes of IDD is the degradation of the extracellular matrix (25). MMPs and tissue inhibitors of metalloproteinases (TIMPs) have an important role in degradation of the extracellular matrix in IVD $(3,10,26)$. Previous studies have shown that IL-17 upregulates the expression of MMP-1/13 in chondrocytes and synovial fibroblasts, enhances the enzyme activity of aggrecanase and collagenase and the monocyte-induced damage of the cartilage matrix, promotes the degradation of cartilage proteoglycan and collagen, and suppresses the synthesis of cartilage proteoglycan $(19,20,27,28)$. Recent studies have suggested that TNF- $\alpha$ may stimulate IVD cells to produce MMP-3, and that MMP-3 can degrade not only the glycoprotein matrix (including fibronectin, laminin and gelatin) and proteoglycans, but also type II collagen and elastin, thereby increasing IDD (29-31). Therefore, IL-17 and TNF- $\alpha$ may both be involved in the progression of IDD. The aim of the present study was to examine the expression of IL-17 and TNF- $\alpha$ and their association with IDD, in order to further understand the pathogenesis of IDD and provide valuable clinical information for the treatment of $\mathrm{LDH}$.

\section{Materials and methods}

Ethical statement. The present study was approved by the Institutional Review Board of the Third Affiliated Hospital of Guangzhou Medical University (Guangzhou, China). Informed written consent was obtained from each eligible patient and the study was performed in accordance with the Declaration of Helsinki.

Subjects and study design. A total of 40 patients with LDH (26 male and 14 female; mean age, $35.82 \pm 12.45$ years; age range, 21-65 years) admitted to the Department of Orthopedics at the Third Affiliated Hospital of Guangzhou Medical University between November 2011 and May 2012 were included in the present study. The diagnosis of LDH was confirmed by clinical manifestation, medical history, clinical examinations and imaging examinations, as well as lower nucleus signal on T2-weighted (TW2) magnetic resonance imaging (MRI). IVD tissue samples, comprising nucleus pulposus tissue, were surgically removed from the 40 patients with $\mathrm{LDH}$, and designated as the experimental group samples. According to the classification of the North American Spine Society (32) and clinical experience, the experimental tissue samples were further divided into an annulus fibrosus disrupted group (18 samples with a ruptured external annulus) and an annulus fibrosus undisrupted group (22 samples with an intact external annulus). Five patients had L3-4 intervertebral segment LDH, 24 patients had L4-5 LDH and 11 patients had L5-S1 LDH.

The present study also included a control group comprising 10 patients with lumbar vertebra fractures ( 7 male and 3 female; mean age, $34.55 \pm 13.23$ years; age range, $21-65$ years), who were examined by MRI and exhibited normal signals from the lumbar discs. The patients were admitted to the Department of Orthopedics of the Third Affiliated Hospital of Guangzhou Medical University between November 2011 and May 2012. Traumatic lumbar disc tissue (nucleus pulposus) samples were surgically removed from patients with lumbar vertebra fractures and designated as the control group. One patient exhibited L3-4 intervertebral segment LDH, 7 patients had L4-5 LDH, and 2 patients had L5-S1 LDH.

MRI grading. The IDD tissue samples were examined by TW2 MRI and divided into five grades (Table I) according to the modified Pearce Standard (33): Grades I and II indicated normal discs, and grades III-V indicated degenerated discs. The tissue samples in this experiment were classified as grade I $(n=6)$, grade II $(n=4)$, grade III $(n=14)$, grade IV $(n=13)$ and grade $\mathrm{V}(\mathrm{n}=13)$ on the basis of MRI grading.

Pathological data. The lumbar disc tissue samples were randomly divided into two groups: One was used for hematoxylin and eosin (H\&E) staining and immunohistochemical staining following fixing with neutral formaldehyde solution, embedding with paraffin, and sectioning, and the other was used for semi-quantitative reverse transcription polymerase chain reaction (RT-PCR) by immersion in liquid nitrogen.

$H \& E$ staining. The LDH tissue sections were fixed in $4 \%$ paraformaldehyde (Linyi Lixing Chemical Co., Ltd., Linyi, China) 
for $48 \mathrm{~h}$ at room temperature, embedded in paraffin using an embedding apparatus (SYD-B; Shenyang Tianrong Cable Material Co., Ltd., Shenyang, China) and incubated at $60^{\circ} \mathrm{C}$ for $3 \mathrm{~h}$. Tissues were then cut (RM2135; Leica Microsystems, Wetzlar, Germany) into $4 \mu \mathrm{m}$ sections. The tissue sections were then deparaffinized in twice in xylene solution (Shanghai Jiuyi Chemical Reagent Co., Ltd., Shanghai, China) for $15 \mathrm{~min}$ prior to being rehydrated by immersion in descending grades of ethanol (absolute ethanol twice for $5 \mathrm{~min}$; $100 \%$ ethanol for $5 \mathrm{~min}$; 80\% ethanol for $5 \mathrm{~min}$; and $70 \%$ ethanol for $5 \mathrm{~min}$; Anhui Ante Biological Chemical Co., Ltd., Anhui, China), and washed three times with distilled water for $2 \mathrm{~min}$. The tissue sections were stained using H\&E (Anhui Ante Biological Chemical Co., Ltd.), washed with running water for $2 \mathrm{~min}$, dehydrated with ethanol, vitrified with xylene and sealed on glass coverslips with gum (Beijing Zhongshan Golden Bridge Biotechnology Co., Ltd., Beijing, China). The tissue sections were then observed under a microscope (BX51; Olympus Corporation, Tokyo, Japan) and the staining results were recorded.

Immunohistochemical staining. Immunohistochemical staining was performed on the paraffin-embedded tissue sections. Following incubation at $60^{\circ} \mathrm{C}$ for $10 \mathrm{~min}$, the tissue sections were deparaffinized twice in xylene for $10 \mathrm{~min}$, hydrated in descending grades of ethanol (100, 90, 75 and 50\% ethanol for $5 \mathrm{~min}$ each), immersed in distilled water for $5 \mathrm{~min}$ and rinsed three times with phosphate-buffered saline (PBS) for $3 \mathrm{~min}$ (pH 7.4; Beijing Dingguo Changsheng Biotechnology Co. Ltd., Beijing, China). Subsequently, the tissue sections were incubated with 3\% peroxidase-blocking agent (Guduo Biotechnology Corporation, Shanghai, China) for $15 \mathrm{~min}$ at room temperature to eliminate endogenous peroxidase activity, and washed again three times with PBS for $3 \mathrm{~min}$ ( $\mathrm{pH}$ 7.4). Each tissue section was incubated with $50 \mu \mathrm{l}$ primary rabbit monoclonal antibody against IL-17 (1:50; ab83688, Abcam, Cambridge, MA, USA) at $37^{\circ} \mathrm{C}$ for $1 \mathrm{~h}$, and then with $50 \mu \mathrm{l}$ biotin-labeled rabbit polyclonal secondary antibody against TNF- $\alpha$ (1:200; ab6671, Abcam) and $50 \mu 1$ horseradish peroxidase streptavidin solution $(1: 400$; Beijing Dingguo Changsheng Biotechnology Co. Ltd.) at $37^{\circ} \mathrm{C}$ for $40 \mathrm{~min}$. The tissue sections were washed three times with PBS for 3 min ( $\mathrm{pH} 7.4$ ) following each incubation. Subsequently, diaminobenzidine was added and the tissue sections were observed under a microscope. Finally, the tissue sections were rinsed with tap water, counterstained using hematoxylin, dehydrated with an ethanol gradient and sealed with neutral gum. Staining in the cytoplasm was recorded according to the following criteria: Brown/yellow, positive; dark brown/yellow, strongly positive; light brown/yellow, weakly positive; no staining, negative.

Semi-quantitative RT-PCR. Total RNA $(5 \mu \mathrm{l})$ of the lumbar IVD tissue samples was isolated using TRIzol ${ }^{\circledR}$ reagent (Takara Bio, Inc., Otsu, Japan) and an ultra-violet spectrophotometer (model Q5000; Bruker BioSpin, Fällanden, Switzerland) was used to measure the concentration and purity of the RNA samples with $\mathrm{OD}_{260} / \mathrm{OD}_{280}$. Agarose gel electrophoresis was then used to examine the integrity of the RNA samples. To avoid adverse effects of genomic/contaminating DNA on reverse transcription, a deoxyribonuclease I
Table II. Primers.

Length of

Gene Sequences $\left(5^{\prime} \rightarrow 3^{\prime}\right) \quad$ products $(b p)$

GAPDH AGAAGGCTGGGGCTCATTTG 258 AGGGGCCATCCACAGTCTTC

IL-17 TGCCTTCAAGACTGAACAC

254 TCTCTGAGGGGCCTTAATC

TNF- $\alpha \quad$ CAATCCCTTTATTACCC

293

GTCTTCTCAAGTCCTGC

GADPH, glyceraldehyde-3-phosphate dehydrogenase; IL-17, interleukin-17; TNF- $\alpha$, tumor necrosis factor- $\alpha$.

kit (Sigma-Aldrich, St. Louis, MO, USA) was used to digest DNA in the total RNA samples according to the manufacturer's protocol. cDNA was synthesized from total RNA samples using a ReverTra Ace qPCR RT kit (Toyobo Co., Ltd., Osaka, Japan) and the product was stored at $-20^{\circ} \mathrm{C}$ until further usage. RT-PCR was performed using the SYBR Green Real-Time PCR Master Mix Kit (Toyobo Co. Ltd.) according to the manufacturer's protocol. The reaction solution $(50 \mu \mathrm{l})$ consisted of $12 \mu \mathrm{l}$ DEPC water, $25 \mu \mathrm{l}$ THUNGERBIRD SYBR qPCR Mix, $1 \mu 1$ forward primer, $1 \mu 1$ reverse primer, $1 \mu 1$ 50X ROX reference dye and $10 \mu 1$ cDNA solution. The amplification conditions were as follows: 1 Cycle of $50^{\circ} \mathrm{C}$ for $2 \mathrm{~min}$ and $95^{\circ} \mathrm{C}$ for $5 \mathrm{~min}$; followed by 40 cycles of $95^{\circ} \mathrm{C}$ for $15 \mathrm{sec}$ and $60^{\circ} \mathrm{C}$ for $1 \mathrm{~min}$. Gene amplification was performed on an ABI PRISM 7000 Sequence Detection System (Applied Biosystems; Thermo Fisher Scientific, Inc., Waltham, MA, USA). After the completion of amplification, melting curves were obtained by heating to $60^{\circ} \mathrm{C}$ to verify the PCR products. The whole sequence of mRNA for each target gene was obtained from the GenBank sequence database and Primer 5.0 software (Premier Biosoft, Palo Alto, CA, USA) was used to design the primer sequences. The primers used in the present study are presented in Table II. All primers were purchased from Beijing Dingguo Changsheng Biotechnology Co., Ltd. Absorbance value (A) was measured using an image analysis system (JS2012; Beijing Maisiqi High-Tech Co., Ltd., Beijing, China), and the relative amount of IL-17 or TNF- $\alpha$ mRNA was expressed as IL-17/ $\beta$-actin or TNF- $\alpha / \beta$-actin.

Statistical analysis. All data were expressed as means \pm standard deviation, and all statistical analyses were performed using SPSS software, version 11.5 (SPSS, Inc., Chicago, IL, USA). Correlation between two variables was analyzed with Pearson's correlation analysis. One-way analysis of variance was used for comparison between multiple groups and least significant difference (LSD) t-test for comparisons between two groups. $\mathrm{P}<0.05$ was considered to indicate a statistically significant difference.

\section{Results}

$H \& E$ staining. As shown in Fig. 1, the cell density in the IVD tissue samples was lower and the distribution of the 
A

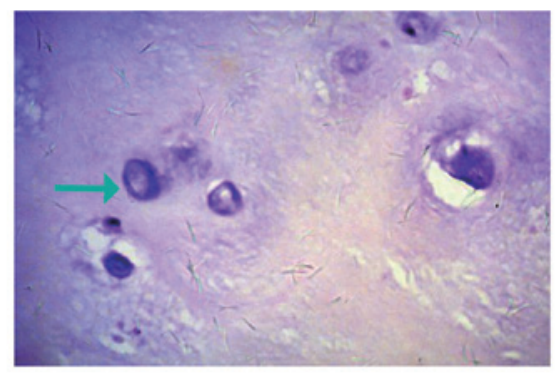

B

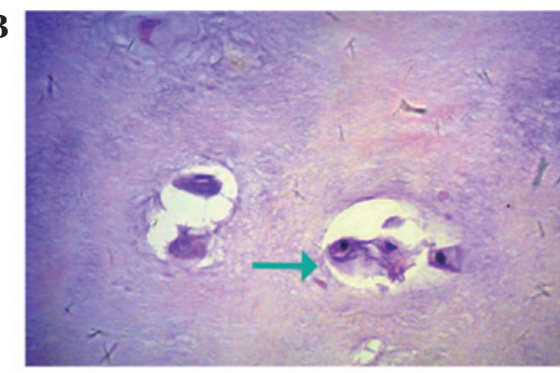

Figure 1. Density and distribution of the cell population in the intervertebral disc tissue samples. (A) Chondrocytes of the lumbar intervertebral disc nucleus pulposus in a control tissue sample and (B) cartilage cells in the posterior outer ring of the ruptured and non-ruptured lumbar intervertebral disc in an experimental tissue sample. Arrow = cartilage collapse. Hematoxylin and eosin staining.
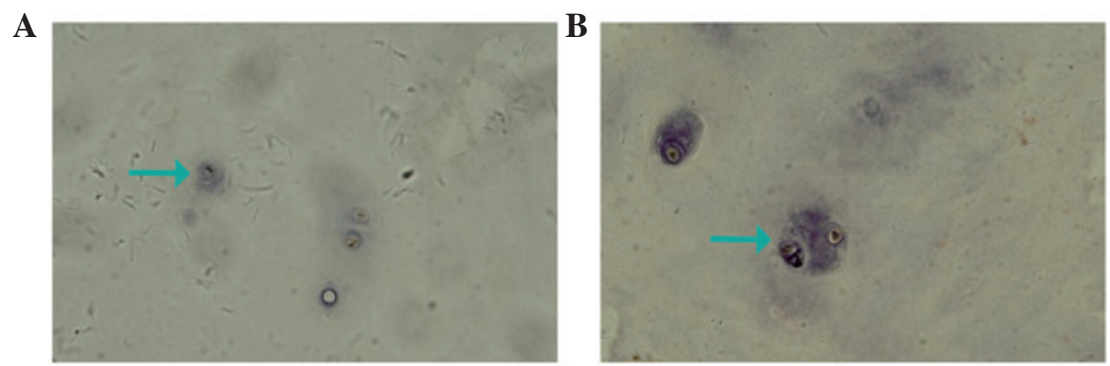

Figure 2. Expression of interleukin-17 in intervertebral disc nucleus pulposus tissue samples as observed by immunohistochemical staining of (A) lumbar intervertebral disc nucleus pulposus tissue in a control tissue sample and (B) cartilage cells in the posterior outer ring of the disrupted and non-disrupted lumbar intervertebral disc in an experimental tissue sample. Arrow = positive expression of interleukin-17.

A

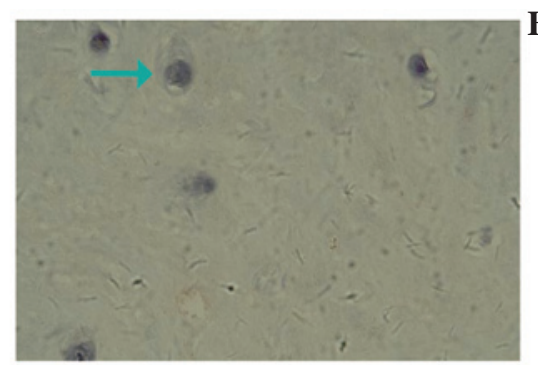

B

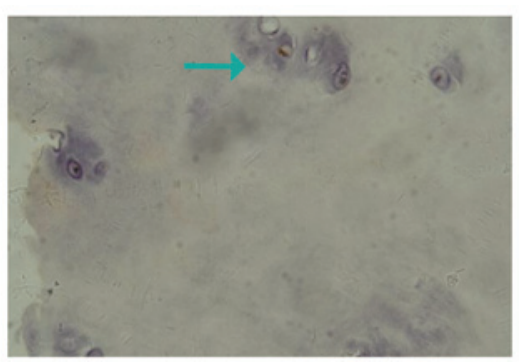

Figure 3. Expression of tumor necrosis factor- $\alpha$ in intervertebral disc nucleus pulposus tissue samples of (A) lumbar intervertebral disc nucleus pulposus tissue in a control tissue sample and (B) cartilage cells in the posterior outer ring of the disrupted and undisrupted lumbar intervertebral disc in an experimental tissue sample.

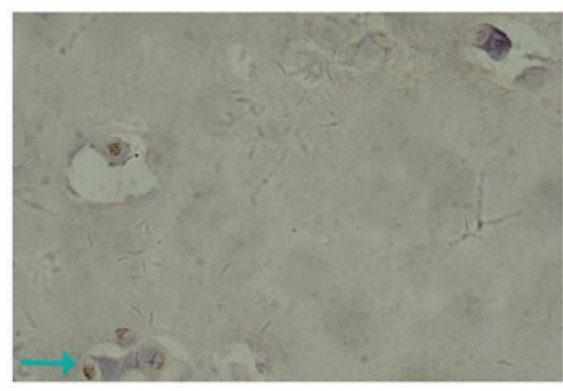

Figure 4. Interleukin-17 expression in the cytoplasm of intervertebral disc nucleus pulposus tissue samples without annulus fibrosus disruption.

cell population was markedly inhomogeneous. In the control group, orbicular-ovate cartilage cells in normal lumbar IVD presented irregular cartilaginous lacunae. In addition, the majority of nucleus pulposus cells were isolated in the cellular

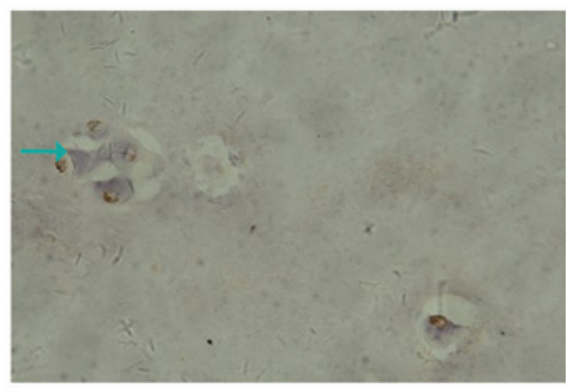

Figure 5. Tumor necrosis factor- $\alpha$ expression in the cytoplasm of intervertebral disc nucleus pulposus tissue samples without annulus fibrosus disruption.

lacunae, with a few multinucleated giant cells and cell clusters occasionally present (Fig. 1A). In the experimental group, $H \& E$ staining revealed that vacuolation in the cytoplasm of the degenerate nucleus pulposus cells occurred with large clones 


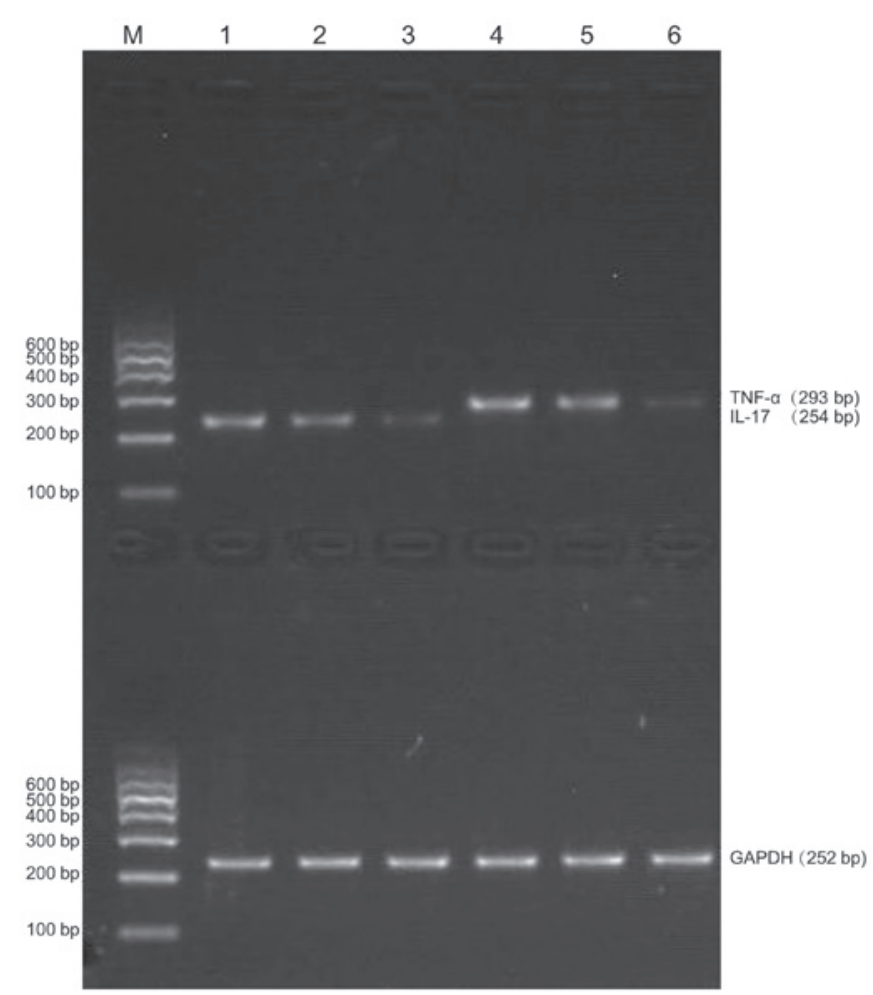

Figure 6. Reverse transcription-polymerase chain reaction results of TNF- $\alpha$ and IL-17 mRNA expression in experimental and control groups. M, marker; 1 , mRNA expression of IL-17 in the external annulus fibrosus disrupted type of the degeneration group; 2, mRNA expression of IL-17 in the external annulus fibrosus undisrupted type of the degeneration group; 3 , mRNA expression of IL-17 in the trauma group; 4, mRNA expression of TNF- $\alpha$ in the external annulus fibrosus disrupted type of the degeneration group; 5 , mRNA expression of TNF- $\alpha$ in the external annulus fibrosus undisrupted type of the degeneration group; 6 , mRNA expression of TNF- $\alpha$ in the trauma group. TNF- $\alpha$, tumor necrosis factor- $\alpha$; IL-17, interleukin-17.

of hypertrophic chondrocytes, located in nested structures. In addition, these large clones of hypertrophic chondrocytes often appeared surrounding the cracks in the IVD. The appearance of cracks in the IVDs was an important marker for degeneration of the IVD (Fig. 1B).

Protein expression of $I L-17$ and TNF- $\alpha$. Fig. 2A and 3A show the expression of IL-17 and TNF- $\alpha$, respectively, in the IVD nucleus pulposus tissue samples of the control group. It was observed that IL-17 and TNF- $\alpha$ in the cytoplasm presented light yellow/brown staining, suggesting weakly positive expression. In the experimental group, IL-17 and TNF- $\alpha$ expression in the cytoplasm of the IVD nucleus pulposus tissue samples with annulus fibrosus disruption presented dark yellow/brown staining, which suggested high positive expression (Figs. 2B and 3B). In addition, IL-17 and TNF- $\alpha$ in the cytoplasm of IVD nucleus pulposus tissue samples without annulus fibrosus disruption in the experimental group exhibited positive expression, presenting yellow/brown or red/brown staining (Figs. 4 and 5).

$m R N A$ expression levels of IL-17 and TNF- $\alpha$. TNF- $\alpha$ and IL-17 mRNA expression levels were examined by RT-PCR, which showed TNF- $\alpha$ and IL-17 mRNA expression in both experimental and control tissue samples. Agarose gel electrophoresis

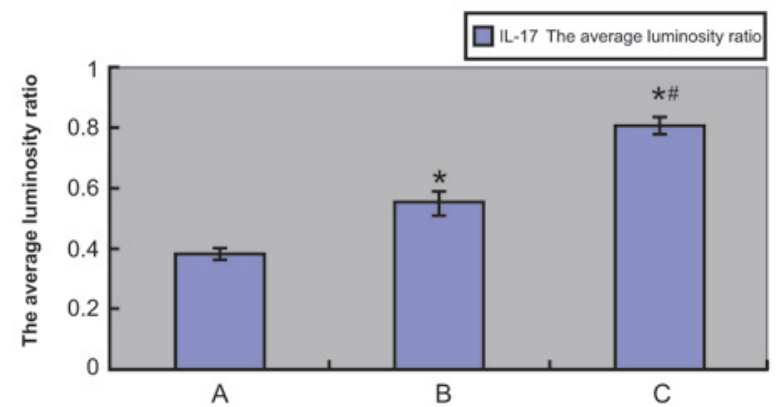

Figure 7. Absorbance value of IL-17 compared with the internal reference. IL-17, interleukin-17; A, control group; B, external annulus fibrosus undisrupted group; $\mathrm{C}$, external annulus fibrosus disrupted group. ${ }^{*} \mathrm{P}<0.01$ vs. the control group; ${ }^{\mathrm{P}}<0.01$ vs. group $\mathrm{B}$.

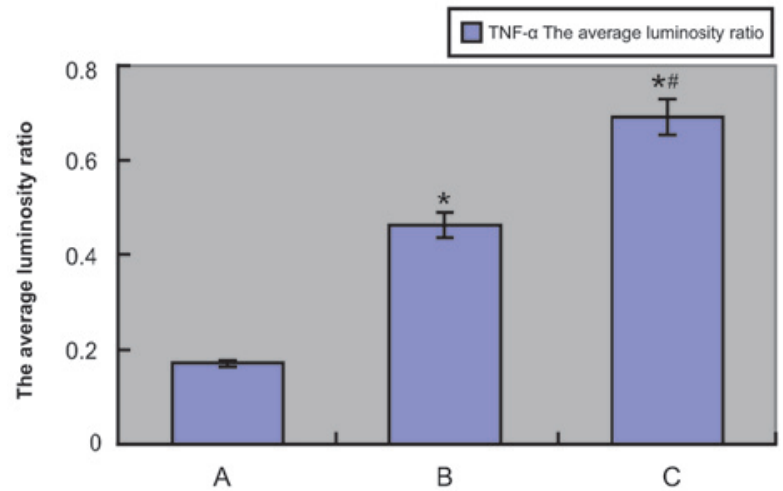

Figure 8. Absorbance value of TNF- $\alpha$ compared with the internal reference. TNF- $\alpha$, tumor necrosis factor- $\alpha$; A, control group; B, external annulus fibrosus undisrupted group; $\mathrm{C}$, external annulus fibrosus disrupted group. ${ }^{*} \mathrm{P}<0.01$ vs. the control group; ${ }^{\#} \mathrm{P}<0.01$ vs. group $\mathrm{B}$.

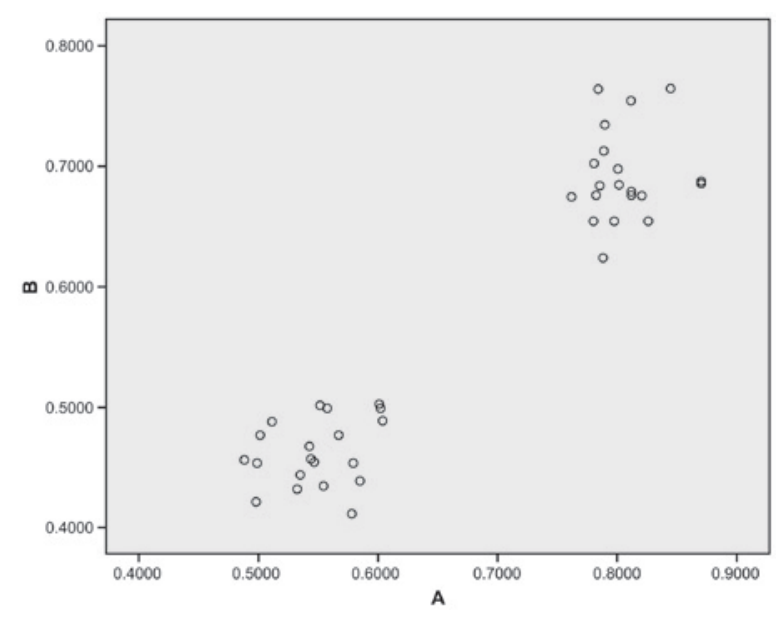

Figure 9. Correlation between IL-17 and TNF- $\alpha$ mRNA expression in the experimental group. TNF- $\alpha$, tumor necrosis factor- $\alpha$; IL-17, interleukin-17; A, absorption value of IL-17 mRNA; B, absorption value of TNF- $\alpha$ mRNA.

demonstrated that the sizes of the PCR-amplified products of TNF- $\alpha$, IL-17 and GAPDH were 293, 254 and 252 bp, respectively (Fig. 6). The absorbance values of IL-17 and TNF- $\alpha$ compared with those of the internal reference (GAPDH) are shown in Figs. 7 and 8, respectively, and also in Tables III and IV, respectively. The IL-17 mRNA expression levels 
Table III. Interleukin-17 mRNA expression in the various groups.

\begin{tabular}{lccc}
\hline Group & No. & Absorbance (mean \pm SD) & F-value \\
\hline Control group & 16 & $0.3981 \pm 0.0190$ & 889.5 \\
Annulus fibrosus undisrupted group & 24 & $0.5762 \pm 0.0383^{\mathrm{a}, \mathrm{b}}$ & $<0.01$ \\
Annulus fibrosus disrupted group & 19 & $0.8464 \pm 0.0307^{\mathrm{a}}$ &
\end{tabular}

${ }^{\mathrm{a}} \mathrm{P}<0.01$ vs. the control group; ${ }^{\mathrm{b}}<0.01 \mathrm{vs}$. the annulus fibrosus fracture group. $\mathrm{SD}$, standard deviation.

Table IV. Tumor necrosis factor- $\alpha$ mRNA expression in the various groups.

\begin{tabular}{lccc}
\hline Group & No. & Absorbance (mean \pm SD) & F-value \\
\hline Control group & 10 & $0.1788 \pm 0.0051$ & $1,512.0$ \\
Annulus fibrosus undisrupted group & 22 & $0.4858 \pm 0.0292^{\mathrm{a}, \mathrm{b}}$ & $<0.01$ \\
Annulus fibrosus disrupted group & 18 & $0.7263 \pm 0.0396^{\mathrm{a}}$ & \\
\hline
\end{tabular}

${ }^{\mathrm{a}} \mathrm{P}<0.01$ vs. the control group; ${ }^{\mathrm{b}}<0.01$ vs. the annulus fibrosus fracture group. $\mathrm{SD}$, standard deviation.

in the annulus fibrosus disrupted group and annulus fibrosus undisrupted group were significantly higher compared with that of the control group $(0.7263 \pm 0.0396$ and $0.4858 \pm 0.0292$, respectively, vs. $0.1788 \pm 0.0051 ; \mathrm{P}<0.01$ for both). As shown in Table IV, the TNF- $\alpha$ mRNA expression levels in the annulus fibrosus disrupted group and annulus fibrosus undisrupted group were both significantly higher compared with that of the control group $(0.8061 \pm 0.0292$ and $0.5488 \pm 0.0365$, respectively, vs. $0.3791 \pm 0.0181 ; \mathrm{P}<0.01$ for both). Furthermore, IL-17 and TNF- $\alpha$ mRNA expression levels in the annulus fibrosus disrupted group were both significantly higher compared with that in the annulus fibrosus undisrupted group (both $\mathrm{P}<0.01$ ). The LSD t-test demonstrated a significant difference in TNF- $\alpha$ and IL-17 mRNA expression levels between the experimental and control groups and between the annulus fibrosus disrupted and annulus fibrosus undisrupted groups (all $\mathrm{P}<0.05$; Table III and IV).

Correlation analysis of $I L-17$ and TNF- $\alpha$ mRNA expression. Fig. 9 demonstrates a correlation between IL-17 and TNF- $\alpha$ mRNA expression in the experimental group. The average luminosity ratio of IL-17 mRNA expression to TNF- $\alpha$ mRNA expression suggested a positive correlation between IL-17 and TNF- $\alpha$ mRNA expression $(r=0.957 ; \mathrm{P}<0.01)$.

\section{Discussion}

The results of present study demonstrate that IL-17 may have an important role during the pathological process of the degeneration of LDH, and the expression levels of IL-17 may be associated with the severity of IDD. IL-17 is a known pro-inflammatory cell factor that regulates and promotes the secretion of various inflammatory mediators, and underlies the pathogenesis of various types of inflammatory diseases, including acute and chronic inflammation (27). Due to its strong pro-inflammatory properties, IL-17 is the initiation factor for numerous inflammatory cytokines and is closely associated with inflammatory diseases, including infection, tumors, allergies, transplantation and autoimmune diseases, particularly allergic and autoimmune diseases (34-36). The basic pathology of $\mathrm{LDH}$ is thought to be extracellular matrix degradation, during which MMPs and TIMPs have an important role in disc extracellular matrix degradation (37). Furthermore, IL-17 upregulates the expression of MMP-1/3 in chondrocytes and synovial fibroblasts, and is able to enhance the activity of aggrecanase and collagen, thereby promoting the degeneration of proteoglycans and collagen in chondrocytes (38). Therefore, IL-17 may be involved in the progression of IDD, although the mechanism underlying this process remains to be determined, and may contribute to the development of IDD.

The results of the present study also indicated that TNF- $\alpha$ may take part in the process of IDD, and its expression levels may be associated with the severity of IDD. Several studies have demonstrated that TNF- $\alpha$, a precursor protein synthesized by catalysis of the TNF- $\alpha$-converting enzyme and predominantly secreted by mononuclear cells and macrophages, is a vital cytokine in immunity, cellular homeostasis, inflammation, and tumor progression $(39,40)$. TNF- $\alpha$ may stimulate IVD cells to produce MMP-3, which can degrade the glycoprotein matrix (composed of laminin, gelatin and fibronectin and elastin), as well as type II collagen, thereby increasing IDD (29-31). In the present study, the protein and mRNA expression levels of TNF- $\alpha$ were higher in the experimental group compared with the control group, which indicates that TNF- $\alpha$ may be associated with IDD.

The mRNA and protein expression levels of IL-17 and TNF- $\alpha$ exhibited a positive correlation; previous studies indicate that this may be due to TNF- $\alpha$ increasing the mRNA stability of IL-17 and increasing its protein expression levels $(19,41,42)$. The present study conducted clinical correlation analyses on the expression levels of IL-17 and TNF- $\alpha$ in degenerative IVD tissue samples, and determined that the two cytokines were positively correlated; this is in agreement with previous studies $(22,43)$. Although the results of the present 
study identified that IL-17 and TNF- $\alpha$ were associated, they did not demonstrated that they exhibit synergistic effects in the pathological processes of IDD; however, previous studies have demonstrated synergistic effects, therefore further research to the current study is required $(19,27)$. These results suggest that IVD cells could produce greater quantities of inflammatory mediators on the cell surface in response to the stimulatory effect of the pro-inflammatory cytokines IL-17 and TNF- $\alpha(28,44)$. In addition, a possible mechanism underlying the synergistic effects of IL-17 and TNF- $\alpha$ may be that exposure to TNF- $\alpha$ results in an increase of IL-17 expression levels, with the upregulated IL-17 expression being indicative of IDD in the tissue samples; in addition, TNF- $\alpha$ may stabilize mRNA or cellular transcription processes $(41,45)$.

In conclusion, the results of the present study demonstrated that IL-17 and TNF- $\alpha$ are potentially involved in the pathological processes of IDD with positive correlation, and these cytokines may have synergistic effects. Thus they may act as novel targets for the prevention and treatment of IDD, and act as pathological references for future studies. Further clinical and genetic studies are required in order to elucidate the etiology and pathogenesis underlying the effects of IL-17 and TNF- $\alpha$ on IDD.

\section{References}

1. Brueck M, Koerholz D, Nuernberger W, Juergens H, Goebel U and Wahn V: Elimination of l-asparaginase in children treated for acute lymphoblastic leukemia. Dev Pharmacol Ther 12: 200-204, 1989.

2. Zou F, Jiang J, Lu F, Ma X, Xia X, Wang L and Wang H: Efficacy of intradiscal hepatocyte growth factor injection for the treatment of intervertebral disc degeneration. Mol Med Rep 8: 118-122, 2013

3. Siemionow K, An H, Masuda K, Andersson G and Cs-Szabo G: The effects of age, sex, ethnicity and spinal level on the rate of intervertebral disc degeneration: A review of 1712 intervertebral discs. Spine (Phila Pa 1976) 36: 1333-1339, 2011.

4. Xie P, Liu B, Chen R, Yang B, Dong J and Rong L: Comparative analysis of serum proteomes: Identification of proteins associated with sciatica due to lumbar intervertebral disc herniation. Biomed Rep 2: 693-698, 2014.

5. Vural C and Yorukoglu D: Comparison of patient satisfaction and cost in spinal and general anesthesia for lumbar disc surgery. Turk Neurosurg 24: 380-384, 2014

6. Ma D, Liang Y, Wang D, Liu Z, Zhang W, Ma T, Zhang L, Lu X and Cai Z: Trend of the incidence of lumbar disc herniation: Decreasing with aging in the elderly. Clin Interv Aging 8: 1047-1050, 2013.

7. Moliterno JA, Knopman J, Parikh K, Cohan JN, Huang QD, Aaker GD, Grivoyannis AD, Patel AR, Härtl R and Boockvar JA Results and risk factors for recurrence following single-level tubular lumbar microdiscectomy. J Neurosurg Spine 12: 680-686, 2010.

8. Hirose Y, Chiba K, Karasugi T, Nakajima M, Kawaguchi Y, Mikami Y, Furuichi T, Mio F, Miyake A, Miyamoto T, et al: A functional polymorphism in THBS2 that affects alternative splicing and MMP binding is associated with lumbar-disc herniation. Am J Hum Genet 82: 1122-1129, 2008.

9. Kim KT, Park SW and Kim YB: Disc height and segmental motion as risk factors for recurrent lumbar disc herniation. Spine (Phila Pa 1976) 34: 2674-2678, 2009.

10. Zhao B, Yu Q, Li H, Guo X and $\mathrm{He} X$ : Characterization of microRNA expression profiles in patients with intervertebral disc degeneration. Int J Mol Med 33: 43-50, 2014.

11. Zhang YG, Zhang F, Sun Z, Guo W, Liu J, Liu M and Guo X: A controlled case study of the relationship between environmental risk factors and apoptotic gene polymorphism and lumbar disc herniation. Am J Pathol 182: 56-63, 2013.

12. Purmessur D, Walter BA, Roughley PJ, Laudier DM, Hecht AC and Iatridis $\mathrm{J}$ : A role for $\mathrm{TNF} \alpha$ in intervertebral disc degeneration: A non-recoverable catabolic shift. Biochem Biophys Res Commun 433: 151-156, 2013
13. Andrade P, Hoogland G, Garcia MA, Steinbusch HW, Daemen MA and Visser-Vandewalle V: Elevated IL-1 $\beta$ and IL-6 levels in lumbar herniated discs in patients with sciatic pain. Eur Spine J 22: 714-720, 2013.

14. Xu D, Sun Y, Bao G, Liu W, Zhu X, Cui S, Fan J and Cui Z: MMP-1 overexpression induced by IL-1 $\beta$ : Possible mechanism for inflammation in degenerative lumbar facet joint. J Orthop Sci 18: 1012-1019, 2013.

15. Onishi RM and Gaffen SL: Interleukin-17 and its target genes: Mechanisms of interleukin-17 function in disease. Immunology 129: 311-321, 2010.

16. Iwakura Y, Ishigame H, Saijo S and Nakae S: Functional specialization of interleukin-17 family members. Immunity 34: 149-162, 2011.

17. Kaplan MH, Glosson NL, Stritesky GL, Yeh N, Kinzfogl J, Rohrabaugh SL, Goswami R, Pham D, Levy DE, Brutkiewicz RR, et al: STAT3-dependent IL-21 production from $\mathrm{T}$ helper cells regulates hematopoietic progenitor cell homeostasis. Blood 117: 6198-6201, 2011.

18. Neurath MF and Finotto S: IL-6 signaling in autoimmunity, chronic inflammation and inflammation-associated cancer. Cytokine Growth Factor Rev 22: 83-89, 2011.

19. Gabr MA, Jing L, Helbling AR, Sinclair SM, Allen KD, Shamji MF, Richardson WJ, Fitch RD, Setton LA and Chen J: Interleukin-17 synergizes with IFN $\gamma$ or TNF $\alpha$ to promote inflammatory mediator release and intercellular adhesion molecule-1 (ICAM-1) expression in human intervertebral disc cells. J Orthop Res 29: 1-7, 2011.

20. Chiricozzi A, Guttman-Yassky E, Suarez-Fariñas M, Nograles KE, Tian S, Cardinale I, Chimenti S and Krueger JG: Integrative responses to IL-17 and TNF- $\alpha$ in human keratinocytes account for key inflammatory pathogenic circuits in psoriasis. J Invest Dermatol 131: 677-687, 2011.

21. Leppkes M, Roulis M, Neurath MF, Kollias G and Becker C: Pleiotropic functions of TNF- $\alpha$ in the regulation of the intestinal epithelial response to inflammation. Int Immunol 26: 509-515, 2014.

22. Risbud MV and Shapiro IM: Role of cytokines in intervertebral disc degeneration: Pain and disc content. Nat Rev Rheumatol 10: 44-56, 2014.

23. Chu WM: Tumor necrosis factor. Cancer Lett 328: 222-225, 2013.

24. Fallahi-Sichani M, El-Kebir M, Marino S, Kirschner DE and Linderman JJ: Multiscale computational modeling reveals a critical role for TNF- $\alpha$ receptor 1 dynamics in tuberculosis granuloma formation. J Immunol 186: 3472-3483, 2011.

25. Le Maitre CL, Pockert A, Buttle DJ, Freemont AJ and Hoyland JA: Matrix synthesis and degradation in human intervertebral disc degeneration. Biochem Soc Trans 35: 652-655, 2007.

26. Sun Z, Wang HQ, Liu ZH, Chang L, Chen YF, Zhang YZ, Zhang WL, Gao Y, Wan ZY, Che L, et al: Down-regulated CK8 expression in human intervertebral disc degeneration. Int J Med Sci 10: 948-956, 2013.

27. Miossec P and Kolls JK: Targeting IL-17 and TH17 cells in chronic inflammation. Nat Rev Drug Discov 11: 763-776, 2012.

28. Shamji MF, Setton LA, Jarvis W, So S, Chen J, Jing L, Bullock R, Isaacs RE, Brown C and Richardson WJ: Proinflammatory cytokine expression profile in degenerated and herniated human intervertebral disc tissues. Arthritis Rheum 62: 1974-1982, 2010.

29. Moe KT, Khairunnisa K, Yin NO, Chin-Dusting J, Wong P and Wong MC: Tumor necrosis factor- $\alpha$-induced nuclear factor-kappaB activation in human cardiomyocytes is mediated by NADPH oxidase. J Physiol Biochem 70: 769-779, 2014.

30. Wang YF, Chen PY, Chang W, Zhu FQ, Xu LL, Wang SL, Chang LY, Luo J and Liu GJ: Clinical significance of tumor necrosis factor- $\alpha$ inhibitors in the treatment of sciatica: A systematic review and meta-analysis. PLoS One 9: e103147, 2014.

31. Ślebioda TJ and Kmieć Z: Tumour necrosis factor superfamily members in the pathogenesis of inflammatory bowel disease. Mediators Inflamm 2014: 325129, 2014.

32. Fardon DF, Milette PC; Combined Task Forces of the North American Spine Society, American Society of Spine Radiology, and American Society of Neuroradiology: Nomenclature and classification of lumbar disc pathology. Spine 26: E93-E113, 2001.

33. Pfirrmann CW, Metzdorf A, Zanetti M, Hodler J and Boos N: Magnetic resonance classification of lumbar intervertebral disc degeneration. Spine (Phila Pa 1976) 26: 1873-1878, 2001. 
34. Miossec P: IL-17 and Th17 cells in human inflammatory diseases. Microbes Infect 11: 625-630, 2009.

35. Xu B, Guenther JF, Pociask DA, Wang Y, Kolls JK, You Z, Chandrasekar B, Shan B, Sullivan DE and Morris GF: Promotion of lung tumor growth by interleukin-17. Am J Physiol Lung Cell Mol Physiol 307: L497-L508, 2014.

36. Herold R, Rosenbloom J and Granovsky M: Phylogenetic distribution of enamel proteins: Immunohistochemical localization with monoclonal antibodies indicates the evolutionary appearance of enamelins prior to amelogenins. Calcif Tissue Int 45: 88-94, 1989.

37. Kozaci LD, Guner A, Oktay G and Guner G: Alterations in biochemical components of extracellular matrix in intervertebral disc herniation: Role of MMP-2 and TIMP-2 in type II collagen loss. Cell Biochem Funct 24: 431-436, 2006.

38. Sylvester J, Liacini A, Li WQ and Zafarullah M: Interleukin-17 signal transduction pathways implicated in inducing matrix metalloproteinase-3, -13 and aggrecanase-1 genes in articular chondrocytes. Cell Signal 16: 469-476, 2004.

39. Liu S, Liu S, Wang Y and Liao Z: The P2/P2' sites affect the substrate cleavage of TNF-alpha converting enzyme (TACE). Mol Immunol 62: 122-128, 2014.
40. Wu Y and Zhou BP: TNF-alpha/NF-kappaB/Snail pathway in cancer cell migration and invasion. Br J Cancer 102: 639-644, 2010.

41. Gruber HE, Hoelscher GL, Ingram JA, Norton HJ and Hanley EN Jr: Increased IL-17 expression in degenerated human discs and increased production in cultured annulus cells exposed to IL-1 $\beta$ and TNF- $\alpha$. Biotech Histochem 88: 302-310, 2013

42. Zhu S and Qian Y: IL-17/IL-17 receptor system in autoimmune disease: Mechanisms and therapeutic potential. Clin Sci (Lond) 122: 487-511, 2012.

43. Wang XP: Preliminary study on the relationship between type 2 diabetic patients with atrial fibrillation. Xin Nao Xue Guan Bing Fang Zhi 11: 201-202, 2011 (In Chinese).

44. Hot A, Lavocat F, Lenief V and Miossec P: Simvastatin inhibits the pro-inflammatory and pro-thrombotic effects of IL-17 and TNF- $\alpha$ on endothelial cells. Ann Rheum Dis 72: 754-760, 2013

45. Di Martino A, Merlini L and Faldini C: Autoimmunity in intervertebral disc herniation: From bench to bedside. Expert Opin Ther Targets 17: 1461-1470, 2013. 